\title{
Resolution of isolated syringomyelia after treatment of cervical disc herniation: Association or coincidence?
}

\author{
Yaman ME, Eylen A, Ayberk G \\ Ataturk Training and Research Hospital, Department of Neurosurgery, Ankara, Turkey. \\ mesutemreyaman@hotmail.com
}

\begin{abstract}
Background: Syringomyelia is a fluid-filled tubular cavity within the spinal cord. The exact pathophysiology of syringomyelia remains complex and uncertain.

Material: We present a case of resolution of cervical syringomyelia after cervical disc operation in a follow-up time of 6 months.

Conclusion: Restoration of cerebrospinal fluid flow dynamics between the syrinx and the subarachnoid space via removing the main pathology such as in our reported case, may contribute in resolution of the syrinx cavity (Fig. 3, Ref. 22). Full Text in PDF www.elis.sk. Key words: cervical disc herniation, cerebrospinal fluid flow dynamics, syringomyelia, syrinx resolution, mechanism.
\end{abstract}

Syringomyelia is a fluid-filled tubular cavity within the spinal cord. Although it is generally associated with Chiari type I malformation, spinal tumors or spinal trauma, the pathophysiology is not completely understood (1-11). In order to prevent an irreversible neurologic disease in patients with syringomyelia, early detection, frequent monitoring and proper timing in treatment of the underlying etiology are necessary.

We report a case of a cervicothoracic syringomyelia which reduced after surgical treatment of cervical disc herniation. The origin and implications of this unusual combination are discussed in light of the recent literature to provide an evidence for a possible cause-effect relationship between syringomyelia and cervical disc herniation.

\section{Case Report}

A 46 year-old female was admitted to our hospital with the complaint of neck pain as well as a painful numbness and weakness on the left arm. The medical and family history was unremarkable. Spurling's sign on the left side, motor weakness on the left forearm (muscle power 4/5), paresthesia on the left C7 sensory distribution and hyporeflexia on the triceps were detected with neurological examination. Magnetic resonance imaging (MRI) revealed a cervical disc herniation at the $\mathrm{C} 6 / \mathrm{C} 7$ level and syringomyelia from C6 to T2. Interestingly, Chiari I malformation which is commonly seen with syringomiyelia was not detected (Fig. 1). Anterior cervical microdiscectomy and fusion with a Polyether-etherketone (PEEK) cage were performed at the $\mathrm{C} 6 / \mathrm{C} 7$ level. Postoperative

Ataturk Training and Research Hospital, Department of Neurosurgery, Ankara, Turkey

Address for correspondence: M.E. Yaman, MD, Jeni Bati Mah. 2026. Cad. Batikent Jenimahalle, 06800, Ankara, Turkey.

Phone: +90.505.5947431, Fax: +90.312.2912705
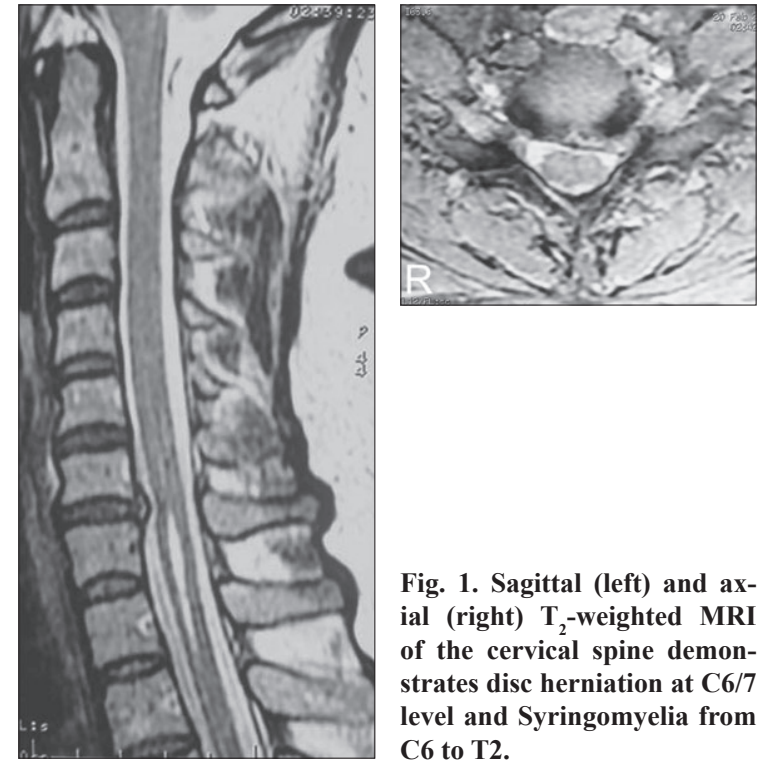

Fig. 1. Sagittal (left) and axial (right) $\mathrm{T}_{2}$-weighted MRI of the cervical spine demonstrates disc herniation at $\mathrm{C} 6 / 7$ level and Syringomyelia from C6 to T2.

examination performed at 3rd month after surgery revealed an improvement in neurological status. The patient had no complaints of pain, weakness and numbness. Postoperative imaging confirmed adequate position of the instrumentation (Fig. 2). Six months after the operation the patient remained asymptomatic, and MRI demonstrated that the syrinx resolved (Fig. 3).

\section{Discussion}

Syringomyelia is a rare disease with an annual incidence of 8.4 cases per 100.000 people $(11,12)$. The mean presentation age of this disease is reported to be between the third and fourth decades of life $(8,13)$. Two types of syringomyelia have been described: 

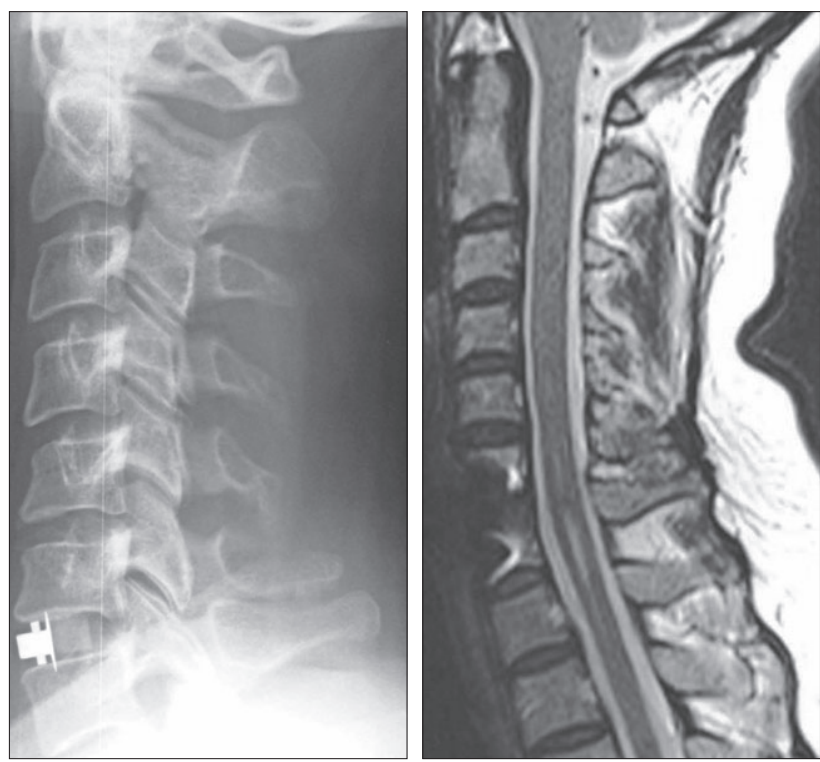

Fig. 2. Postoperative direct X-ray Fig. 3. Sagittal $T_{2}$-weighted MRI of the patient shows adequate posi- of the cervical spine 6 months aftion of the instrumentation.

ter surgery showing cervical canal decompression and resolution of the syrinx.

Cerebrospinal fluid (CSF) filled cystic cavitation within the central canal in communication with the fourth ventricle, and syrinx formation within the cord parenchyma that may or may not extend secondarily to the central canal $(7,11,14)$. Noncommunicating syrinxes, like our reported case, depends upon an obstruction of the CSF pathways that exaggerates the spinal pulse wave and forces fluid under increased pressure into the interstitial spaces of the spinal cord (15).

Syringomyelia is often in association with several pathologies including Chiari I malformation, basilar invagination, intramedullary tumour, spinal cord trauma, tethered cord, cervical spondylosis, disc prolapse, spinal arachnoid cyst, occipital encephalocele, tuberculous meningitis, arachnoiditis and cardiovascular anomalies (2-11). Furthermore there was no radiological evidence of Chiari I or any other craniocervical malformation and no history of trauma and infection in our case.

Although many mechanisms have been described to clarify the syrinx formation, the exact pathogenesis is still unknown $(2,16)$. A widely held theory focuses on local CSF flow which is disturbed within the subarachnoid compartment, creating a pressure gradient that drives fluid accross the perivascular space, thus increasing fluid volume within the extracellular compartment $(11,17)$. This phenomenon can occur in a number of different diseases involving partial restriction of cord mobility and might have developed due to craniospinal pressure dissociation caused by intermittent spinal cord compression (6).

Spontaneous resolutions of syringomyelia have been reported in the literature. However, most of the reported cases of spontaneous resolution of syringomyelia are in association with Chiari malformation and are seen in the pediatric popula- tion $(18,19)$. Enlargement of the posterior fossa with differential growth between the bone structures and the central nervous system leads to Chiari I malformation improvement and resolution of syringomyelia in childhood. In adults, rupture of the syringomyelic cavitiy, rupture of the arachnoid membranes obstructing the CSF flow or cerebellar atrophy can be the cause of resolution of syringomyelia (19). On the other hand, some reports of resolution of syringomyelia with idiopathic origin have also been reported $(20,21,22)$. But the exact mechanism remain controversial. We hyphotezise that craniospinal pressure dissociation as a result of cervical disc herniation, is the cause of syringomyelia in this case. The herniated disc acts as "hammer" on the spinal cord and as a result of extramedullary compression causes change of the CSF pressure leading to transcordal CSF infiltration followed by cavitation. The resolution of the cavity after surgical treatment of cervical disc is the proof of this mechanism.

\section{Conclusion}

The pathophysiology of syringomyelia remains complex and uncertain. It should be kept in mind that careful neurological examination and radiographic imaging is still the most appropriate way of avoiding more diffucult treatment methods. This case is a good evidence for restoration of CSF flow dynamics between the syrinx and the subarachnoid space. Removing the main pathology is the exact and simple treatment of "complex nature diseases" such as in syringomyelia.

\section{References}

1. Ball JR, Little NS. Chiari malformation, cercival disc prolapse and syringomyelia- always think twice. J Clin Neurosci 2008; 15: 474-476.

2. Hsu AR, Hou LC, Veeravagu A, Barnes PD, Huhn SL. Resolution of Syringomyelia after release of tethered cord. Surg Neurol 2009; 72 (6): 657-661.

3. Inoue Y, Nemoto Y, Ohata K, Daikokuya H, Hakuba A, Tashiro T, Shakudo M, Nagai K, Nakayama K, Yamada R. Syringomyelia associated with adhesive spinal arachnoiditis: MRI. Neuroradiology 2009; 43: 325-330.

4. Kaynar MY, Kocer N, Gencosmanoglu BE, Hanci M. Syringomyelia - As a late Complication of Tuberculous Meningitis. Acta Neurochir 2000; 142: 935-939.

5. Kim MS, Kim SH. Syringomyelia Associated with a Spinal Arachnoid Cyst. J Korean Neurosurg Soc 2009; 45: 315-317.

6. Kimura R, Park YS, Nakase H, Sakaki T. Syringomyelia caused by cervical spondylosis. Acta Neurochir (Wien)2004; 146: 175-178.

7. Klekamp J, Batzdorf U, Samii M, Bothe HW. Treatment of syringomyelia associated with arachnoid scarring caused by arachnoiditis or trauma. J Neurosurg 1997; 86: 233-240.

8. Naderi S, Ozgen S, Pamir N. Cervical spondylotic myelopathy associated with syringomyelia: A case Report. Eur J Orthop Surg Traumatol 2000; 10: 203-205. 


\section{0-502}

9. Ohtonoroi T, Nishihara N, Ota T, Kobanawa S, Ota S, Danjo W, Koyama T. Rapid reduction of Syrinx Associated with Traumatic Intracranial Hypotension by Direct Surgery. Neurol Med Chir (Tokyo)2009; 49: 66-70.

10. Park YS, Kimura R, Nakase H, Sakaki T. Three Cases of Syringomyelia due to unusual Causes. J Nara Med Assoc. 2005; 55 (1): 55-60.

11. Porensky P, Muro K, Ganju A. Nontraumatic Cervicothoracic Syrinx as a Cause of Progressive Neurologic Dysfunction. JSCM 2007; 3 (3): 276-281.

12. Di Lorenzo N, Cacciola F. Adult Syringomyelia. Classification, pathogenesis and therapeuruc approaches. J Neurosurg Sci 2005; 49 (3): 65-72.

13. Greenberg MS. Handbook of Neurosurgery, Sixth Edition, Thieme, $350,2006$.

14. Milhorat TH, Capocelli AL Jr, Anzil AP, Kotzen RM, Milhorat RH. Pathological basis of spinal cord cavitation in syringomyelia: analysis of 105 autopsy cases. J Neurosurg 1995; 82: 802-812.

15. Milhorat TH. Is Reversible Enlargement of the Spinal Cord a Presyrinx State? AJNR 1998; 20: 21-22.
16. Williams B. On the pathogenesis of syringomyelia: a review. J Roy Soc Med 1980; 73: 798-806.

17. Brodbelt AR, Stoodley MA, Watling AM, Tu J, Jones NR. Fluid flow in an animal model of post-traumatic syringomyelia. Eur Spine $\mathrm{J}$ 2003; 12: 300-306.

18. Sung WS, Chen YY, Dubey A, Hunn A. Spontaneous regression of syringomyelia- review of the current aetiological theories and implications for surgery. J Clin Neurosci 2008; 15: 1185-1188.

19. Kyoshima K, Bogdanov EI. Spontaneous resolution of Syringomyeli: Report of two cases and review of the literature. Neurosurgery 2003; 53: 762-769.

20. Kastrup A, Nagele T, Topka H. Spontaneous resolution of idiopathic syringomyelia. Neurology 2001; 57: 1519-1520.

21. Ozisik PA, Hazer B, Ziyal IM, Ozcan OE. Spontaneous resolution of syringomyelia without Chiari malformation. Neurol Med Chir (Tokyo) 2006; 46: 512-517.

22. Vinas FC, Pilitsis J, Wilner H. Spontaneous resolution of asyrinx. J Clin Neurosci 2001; 8: 170-172. 